\title{
Insight
}

\section{Production Flexibility in Extensive Beef Farming Systems}

\author{
$\underline{\text { Laura Astigarraga }}^{1}$ and Stéphane Ingrand $^{2}$
}

\begin{abstract}
The aim of this work is to assess the flexibility of production allowed by extensive production conditions faced with variations in the environment, i.e., market variations and climatic fluctuations, of Limousin beef systems. The study used a case-based methodology in which seven beef farms with less than $1 \mathrm{LU} / \mathrm{ha}$ were chosen. Data collection was based on three interviews using a semistructured questionnaire and on the analysis of productive and economic results over a 15-year period (1991-2005). The main evolution of these farms is related to a rise in work productivity associated with an increase in herd size. Herd increase was made possible by enlarging the area, the margin of intensification being limited in these regions. To take advantage of the enlarged land area, females were reared for fattening or for reproduction instead of selling them at weaning. The Limousin female provides a wide product mix because of its plasticity, as has been studied by several researchers. This mix flexibility is achieved by delaying product differentiation, a form of production flexibility that can reduce the risk of under-producing or overproducing varied product configurations. On the other hand, calves sold to the Italian market after weaning are generic products, associated with a flexible production process to overcome fluctuations in forage availability due to climatic variations. The introduction of maize silage for feeding acts as an alternative route, actual and potential, through the system to overcome unexpected forage shortage from natural grasslands as a result of droughts. The study shows that extensive farming systems have developed types of flexibility to match different factors of uncertainty from the environment. Finally, the issue of farm system performance is thus not so much a question of whether a farm is fit at a specific moment in time, but whether it transforms into a less or more sustainable orientation.
\end{abstract}

Key Words: extensive farming system; livestock production system; mix flexibility; process flexibility

\section{INTRODUCTION}

In the last 15 years, European agriculture has been confronted with unprecedented change. The stability of the competitive environment in the 1960s and 1970s has been replaced by increasing uncertainty. Farmers operating in markets are faced with an array of changing contexts (Veysset et al. 2005). These changes relate to large scale and local market movements, variable climate and potential changes in climate, and changes in domestic agricultural policies, i.e., subsidies, incentives, tariffs, insurances. Previous concepts that guided the classical approach of farm management such as stability, income maximization, or biological optimization are increasingly replaced by concepts such as plasticity, adaptability, and flexibility (Darnhofer et al. 2010a). In particular, flexibility can be seen as the system's response to deal with uncertainty (Upton 1994, Corrêa and Slack 1996, Gupta and Somers 1996, Volberda 1996, Scala et al. 2006). The concept of flexibility is frequently used for the analysis of manufacturing firms facing change, but as far as we know in agricultural research, flexibility has not received much attention as a separate issue (Dedieu et al. 2008). In the following discussion, the focus is on flexibility and the dynamics of systems as they adapt to changing circumstances and by doing so, create new opportunities. Indeed, there is no such thing as an ever-stable system and within the context of agriculture, farmers have always lived in changing political, economic, and ecological environments in which surprise and structural change are inevitable (Milestad and Darnhofer 2003) 


\section{Literature review}

In management science, flexibility is a complex and multidimensional concept, and it is the uncertainty in the environment that makes flexibility valuable (Gerwin 1993, Upton 1994). Perceived uncertainty results from a lack of information about environmental factors, an inability to accurately assess environmental probabilities, and a lack of knowledge regarding costs associated with an incorrect decision (Scala et al. 2006). According to Slack (1987), flexibility in a generic sense can be defined as the ability of a system to respond, at a reasonable cost and at an appropriate speed, to planned and unanticipated changes in external and internal environments. The term environment represents the conditions in which the system operates; a system has both an external environment, i.e., outside its boundary, and an internal environment, i.e., inside its boundary. On these bases, it is clear that flexibility is always relative to the goal strived for and to the environmental circumstances. Flexibility, therefore, is not a characteristic of a system itself, but a characteristic of the relationship between a system and its environment, i.e., its measurement and deployment is situation specific (Gupta and Buzacott 1989). Therefore, to assess the flexibility of a system, we need first to determine what the drivers are, i.e., the factors that determine the need for flexibility (Das and Patel 2002, Pujawan 2004).

Based on the work by De Leeuw and Volberda (1996), the definition of flexibility can be expanded to include the idea of control applied to the systems theory. According to these authors, flexibility is the degree to which a system possesses a variety of actual and potential capabilities and the rapidity with which it can implement these capabilities to improve the controllability of the environment. Control is understood here as any manner of directed influence, not defined by its success but by the ascribed intention; this idea must be distinguished from control in the sense of strict determination of processes. Internal flexibility corresponds to low controllability from the environment, i.e., whenever the environment exercises control over the system, it is able to adapt in such a way that this control does not succeed. In this case, greater flexibility can translate into applying new technologies or renewing products as a way of better absorbing disturbances from the environment (Scala et al.
2006). External flexibility means the ability to successfully control the environment, or in more specific terms, high flexibility corresponds to an extensive control capacity of the system with respect to the environment (De Leeuw and Volberda 1996). In this case, the response may be creating new product market combinations or using market power to deter entry and control competitors.

The use of a control perspective results in a distinction between internal and external flexibility, producing changes in the system or in the environment. According to Dreyer and Grønhaug (2004), to defend and improve its competitive position, the firm must exploit opportunities and neutralize $\mathrm{v}$ threats in its competitive environment, i.e., that part of the firm's external environment that consists of other firms fighting for dominance of the same market. It also illustrates that both internal and external flexibility can be either passive or active; this means not only reactive, as adaptation would be, but proactive as well. In the context of flexibility, the word proactive refers to the need to build necessary capabilities into the resources, processes, and structures to manage change. This means the possible changes have to be expected in advance and appropriate types of flexibility should be built to manage the expected change (Wadhwa and Rio 2002). This viewpoint involving control and anticipation processes makes it possible to distinguish the notion of flexibility from the notion of resilience (Holling 1973, Gunderson 2000, Milestad 2003).

According to the study on flexible organizations of Nordic countries, Gjerding (1999) had argued that flexible firms may behave reactively when faced with environmental changes, but they tend to prepare themselves for these events by instituting organizational changes. In other words, managers will try to act ex-post-facto, responding to an unplanned change, but they would frequently prefer to act ex-ante-facto, trying to control the uncertainty and variability of the unplanned changes (Corrêa and Slack 1996). Sometimes the same action can serve both to overcome the fluctuations from the environment and to increase the control. By improving forecasting systems for instance, a firm can reduce the level of uncertainty under which it works but, at the same time, it can prepare itself to respond faster to future customer orders. However, there is also a need to ensure some baseline stability 
for 'rigidity' to allow for flexibility. This aspect is advocated by De Leeuw and Volberda (1996) who argue that the point about flexibility is not to increase flexibility indefinitely, but to find the right mix of rigidities and flexibilities, or to balance change and continuity (Dreyer and Grønhaug 2004).

Considering the agricultural sector, farmers have developed systems that allow them to maintain production within an environment in which physical conditions, in particular the climate, and economic circumstances, i.e., marked prices, may vary from year to year. According to Darnhofer et al. (2010a), the farm is understood as a unit made up of the farmer, with his or her mental models, preferences, goals, abilities, etc., making up its social and cultural capital, and the physical farm, with a variety of subsystems including land, animals, crops, building, finances, etc., making up its natural and economic capital. In the research program Farm Flexibility Confronted With Beef Crises (Ingrand et al. 2007), farm flexibility is defined as the capacity of the livestock system to adjust quickly to a wide range of economic, technical, marketing, and climatic constraints, while allowing the farmer to cope with his/her production plan in the medium term (2-5 years) or even the long term (5-10 years). To remain competitive, flexibility is the process of maintaining various farming objectives, e.g., yield, production, profitability, sustainability, in the face of changes in external or internal conditions. Thus, farm sustainability depends on the farms' ability to absorb the perturbation or to adapt itself to avoid their local consequences. To prevent the buildup of large scale crises, successful farm management will allow disturbances to enter on a scale that does not disrupt the structure and functional performance of the farm and the services it provides, while allowing for internal renewal (Darnhofer et al. 2010b). At the level of the individual farm, we take this to mean primarily that the farm business must remain financially viable while providing an acceptable livelihood for the farm family (Lev and Campbell 1987), without detrimental effects for the agroecosystem. This requires the ongoing development of a portfolio of alternative activities and resource use patterns that can be implemented quickly if needed.

Flexibility can be seen as a quality of adaptive management that emphasizes the importance of understanding feedback from the environment and systematic, i.e., not-random, experimentation in shaping future actions (Milestad and Darnhofer 2003). The issue of farm system flexibility is thus not so much a question of whether a farm is fit at a specific moment in time, but whether the system preserves a relative capacity to respond or conform to changing circumstances (Darnhofer et al. 2010b).

\section{Research proposal}

The research reported here aimed at two complementary objectives. The first was to integrate the concept of flexibility with the responsiveness of extensive beef farming production systems, and the second was to understand the drivers of flexibility and their effect on farm system design.

\section{METHODS}

The Limousin, located in central France (latitude $45.69^{\circ} \mathrm{N}$; longitude $1.62^{\circ} \mathrm{E}$; altitude $350 \mathrm{~m}$ on average), is one of the most rural regions in the country. Limousin's major industry is agriculture, but as the soil is not particularly fertile, livestock, particularly the Limousin breed of cattle, accounts for more than $90 \%$ of total output. The majority of livestock systems are grass-based (Fig. 1).

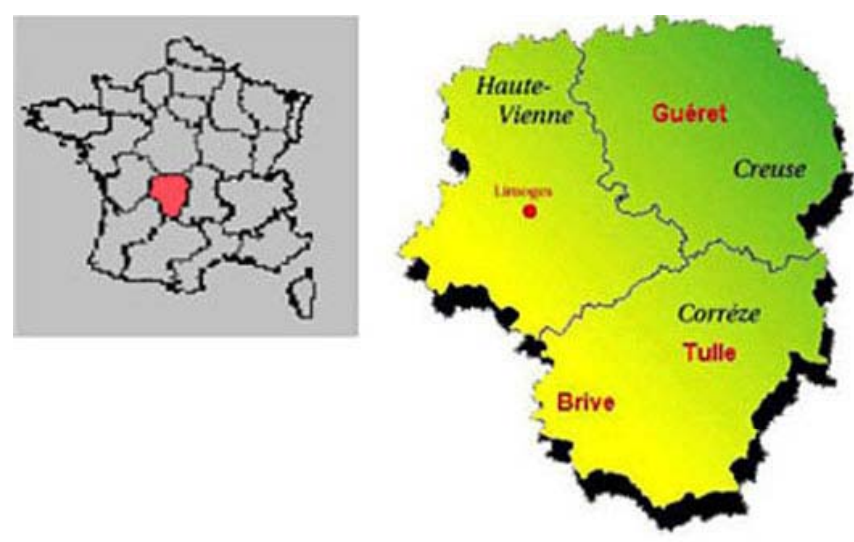

Fig. 1. The Limousin region is one of the most rural regions in France.

The study used a case-based methodology in which seven beef farms were analyzed in depth. These farms had already been studied 15 years ago by 
Josien et al. (1994), therefore there was detailed information on the start of our study period. In Josien et al.'s study, two specific criteria were used to choose the farms: 1 ) their extensive conditions of production (<1 Livestock Unit [LU] / ha); and 2) a high work productivity level (>50 LU / work unit). In our study, data collection was based on three interviews with each farmer, according to the approach of Das and Patel (2002). The total time to complete each questionnaire was estimated to be two-and-half hours.

The first interview, based on a semistructured questionnaire, inquired about the main evolution of the farms in the last 15-year period and attempted to identify the most significant changes that have affected the farm's overall performance according to farmers. This questionnaire contained two main parts: part one described the present situation in terms of land use, labor force, farm inputs supply, herd categories, animal husbandry practices, farm products and sales; part two centered on the main events that induced changes in farm practices to identify the most important drivers. The second interview aimed at explaining what attempts, if any, have been made to counter the detrimental effects of the changes identified during the first interview. The third and last interview consisted of recording and discussing with the farmer the productive and economic results for the 15-year period (1991-2005) to estimate the impact each change has had on the global performance of the farm.

\section{RESULTS AND DISCUSSION}

\section{Main evolution of the farms studied}

The most important general changes observed in the last 15 years, were as follows: increment of land area and livestock, change of productive orientation in some cases, and increase in work productivity (Table 1).

Land area increased in almost all farms (+ 32\%), cereal forage crops tended to diminish (-64\%), and maize silage area increased (from 0\% in 1991 to 3\% in 2005 of the total area). Herd size increased markedly in all areas, and in four cases (farms 2, 3, 6 , and 7), there was also an increase in beef cows $(+35 \%)$. In these latter cases, the incorporation of a new member or associate into the farm gave entitlement to more beef cow premiums and consequently, an increase in the number of cows.
Generally, the changes observed over time can be interpreted as attempts by farmers to adapt to three groups of factors: 1) the general socioeconomic environment, predominantly influenced by agricultural policies; 2) specific local/regional factors relative to farm location; and 3) internal characteristics of the household, including structural, economic, and sociological aspects. In terms of the general socioeconomic context that surrounds ruminant livestock farming in Europe, the Common Agricultural Policy (CAP) plays a central role. CAP 1992, expanded by the Agenda 2000, implemented compensation payments and extensification policies that have caused enlargement of beef farm size (Veysset et al. 2005). A second group of factors determining farming system evolution, relative to less-favored areas like the Limousin, involves a process of abandonment of farming and of changes that occur in the remaining farms. The main reason for the disappearance of farming and subsequent abandonment of large pastoral areas in this region is the lack of continuity in agricultural households (García Martinez et al. 2009). This lack of continuity is directly related to the presence and number of descendants in the household, or might rather be assigned to specific characteristics of farms in the process of disappearance, i.e., in the final stages of their life-cycle.

Labor input (work unit, WU) was maintained or increased in the period of study, but in general, the number of animals handled by a WU increased (+ $21 \%$ ). Orientation of production also changed in this period. The "weaned calf" production as the main activity tended to be complemented with animals (heifers) sold for reproduction, and one farm (farm 6) expanded its activities to fattening (young bulls of 10 to 12 months old). Global Gross Margin (GM $=$ total revenue - variable costs) increased in this period (+ 19\%) as both herd productivity (Beef GM/ LU; + 29\%) and livestock units per farm increased. This was largely determined by the CAP premiums paid on a per head basis. In this way, work productivity (Global GM/WU), which constitutes a crucial indicator of the chances of reproducibility of the farm and therefore its social sustainability, could be maintained or improved. This process is also reported in other mountainous areas in France (Veysset et al. 2005) and Spain (García Martinez et al. 2009).

This structural adjustment, i.e., increase in land area, coupled with agricultural policies, allowed a continuity of extensive livestock management 
Table 1. Structural characteristics of the seven farms studied and changes between 1991 and 2005.

\begin{tabular}{|c|c|c|c|c|c|c|c|c|c|c|c|c|c|c|}
\hline \multirow{2}{*}{$\frac{\text { Farms }}{\text { Year }}$} & \multicolumn{2}{|c|}{1} & \multicolumn{2}{|c|}{2} & \multicolumn{2}{|c|}{3} & \multicolumn{2}{|c|}{4} & \multicolumn{2}{|c|}{5} & \multicolumn{2}{|c|}{6} & \multicolumn{2}{|c|}{7} \\
\hline & 1991 & 2005 & 1991 & 2005 & 1991 & 2005 & 1991 & 2005 & 1991 & 2005 & 1991 & 2005 & 1991 & 2005 \\
\hline total area (ha) & 73 & 80 & 181 & 243 & 125 & 170 & 71 & 71 & 119 & 165 & 178 & 305 & 179 & 190 \\
\hline $\begin{array}{l}\text { grazing area } \\
(\%)\end{array}$ & $100 \%$ & $100 \%$ & $96 \%$ & $98 \%$ & $92 \%$ & $77 \%$ & $94 \%$ & $100 \%$ & $92 \%$ & $95 \%$ & $97 \%$ & $96 \%$ & $90 \%$ & $84 \%$ \\
\hline \multicolumn{15}{|l|}{ Forage crops } \\
\hline cereals (\%) & $0 \%$ & $0 \%$ & $4 \%$ & $0 \%$ & $8 \%$ & $0 \%$ & $6 \%$ & $0 \%$ & $8 \%$ & $5 \%$ & $3 \%$ & $0 \%$ & $10 \%$ & $9 \%$ \\
\hline $\begin{array}{l}\text { maize silage } \\
(\%)\end{array}$ & $0 \%$ & $0 \%$ & $0 \%$ & $2 \%$ & $0 \%$ & $6 \%$ & $0 \%$ & $0 \%$ & $0 \%$ & $0 \%$ & $0 \%$ & $4 \%$ & $0 \%$ & $7 \%$ \\
\hline Beef products & $\mathrm{R}$ & $\mathrm{R}$ & $\mathrm{R}$ & $\mathrm{R}$ & B & $\begin{array}{l}\mathrm{B}+ \\
\mathrm{HR}\end{array}$ & B & B & B & $\begin{array}{l}\mathrm{B}+ \\
\mathrm{HR}\end{array}$ & $\begin{array}{l}\mathrm{B}+ \\
\mathrm{HR}\end{array}$ & $\begin{array}{c}\mathrm{B}+ \\
\mathrm{HR}+ \\
\mathrm{FM}\end{array}$ & $\begin{array}{l}\mathrm{B}+ \\
\mathrm{HR}\end{array}$ & $\mathrm{B}+\mathrm{HR}$ \\
\hline $\begin{array}{l}\text { Other } \\
\text { products }\end{array}$ & 0 & 0 & 0 & 0 & 0 & $\begin{array}{l}\text { maize } \\
\text { grain }\end{array}$ & 0 & 0 & 0 & 0 & sheep & sheep & 0 & 0 \\
\hline beef cows & 45 & 45 & 145 & 191 & 75 & 89 & 42 & 42 & 92 & 96 & 82 & 128 & 81 & 114 \\
\hline SR & 0.89 & 0.81 & 1.03 & 1.04 & 0.83 & 1.00 & 0.89 & 0.86 & 1.00 & 0.82 & 1.01 & 1.27 & 0.83 & 1.09 \\
\hline WU & 1.3 & 1.3 & 3.0 & 3.0 & 1.5 & 2.0 & 1.2 & 1.2 & 2.0 & 2.0 & 2.0 & 2.5 & 2.5 & 2.5 \\
\hline Beef LU/WU & 50 & 50 & 60 & 83 & 64 & 66 & 50 & 51 & 55 & 64 & 56 & 89 & 54 & 69 \\
\hline $\begin{array}{l}\text { Beef GM/ } \\
\text { LU† }\end{array}$ & 925 & 1576 & n.d. & n.d. & 563 & 596 & n.d. & n.d. & 668 & 817 & 683 & 724 & 639 & 789 \\
\hline $\begin{array}{l}\text { Global GM/ } \\
\text { WU (000 } \\
\text { euros) } †\end{array}$ & 66.1 & 76.3 & n.d. & n.d. & 39.4 & 44.3 & n.d. & n.d. & 46.7 & 52.6 & 60.4 & 108.2 & 75.2 & 61.5 \\
\hline
\end{tabular}

LU: livestock unit

SR: stocking rate (LU/grazing area)

WU: work unit (time devoted to farm work by one person during 1 year)

GM: gross margin (subsidies included)

n.d.: no data values

$\mathrm{R}$ : Males and females for reproduction

B: calf sold just after weaning (Broutard)

B + HR: B and females for reproduction

B + HR + FM: B + HR and fattened males.

$\dagger$ Euros 2005 
without deleterious effect on farm income. The enlargement of land area allowed for a wide product mix.

\section{Wider product line (mix flexibility by delayed product differentiation)}

The generic product produced by these extensive farms is the calf sold just after weaning as "Broutard d'Italie", which does not need a high level of energy in the diet as is needed for fattening bulls after weaning, for example. This is why these systems can be $100 \%$ based on grass. However, although the value of the male is considerably enhanced, with the exception of 1996 and 2000's BSE crises, the female is penalized. The heifer has a dual handicap in relation to the male: a lower weight and a lower price/kg Live Weight (LW; Fig. 2). Thus, there is a need to make the best profit from the females, acting as a driver to increase production mix flexibility.

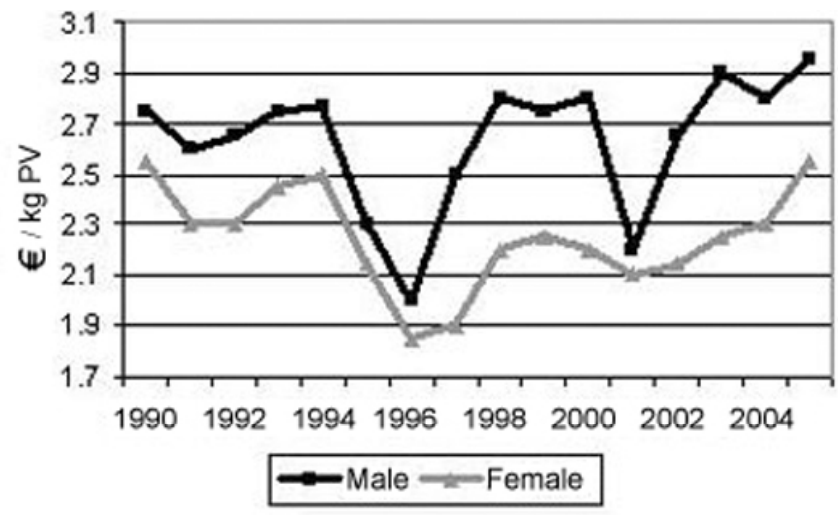

Fig. 2. Evolution of the average price of the "Broutard d'Italie" for the period 1990-2005 (euros 2005), (Brouard 2006).

Farmers have taken advantage of the increased area by rearing the females for fattening or for reproduction because public policies concerning subsidies limit the suckler cow premium per farm. The female in the Limousin system allows a wide product mix because of its plasticity as has been studied by several researchers (Geay and Micol 1982, Dauplais 1996; Fig. 3).
Therefore, though the male is predominantly sold after weaning for the Italian market, the female is sold as different beef products: for fattening (Broutarde d'Italie) or fattened (Génisse de Saint Etienne and Génisse de Lyon), or as a heifer for reproduction (for "Le veau sous la mère" system), or as pregnant heifer for herd replacement. The Limousin female sold for reproduction or fattened for slaughtering improves the gross margin/female in comparison with the female sold for the Italian market. In particular, females sold for reproduction $\left(F_{1-2}\right.$ or $\left.F_{2-3}\right)$, which are reared in the same way as the females for replacement, allow an enhanced value of the grazing area without increasing operating expenses such as extra feed, or specific equipment.

This diversification into several products and the capacity for switching from one product to another allows mix flexibility. In fact, this kind of flexibility is part of ordinary strategies farmers undertake as a way of having a "cushion" effect provided by a broader mix product. As stated by management science, firms that can switch among products for many categories of final products will not be so adversely affected if the demand for one product line shrinks unexpectedly (Suárez et al. 1996). Furthermore, mix flexibility in the Limousin beef farming system is achieved by delaying product differentiation, which is a form of production flexibility that can reduce the risk of underproducing or over-producing varied product configurations (Cattani et al. 2002). Limousin females sold for reproduction or fattened make "delayed differentiation" possible: following the demand and prices, the one-year-old females are differentiated as fattened products or heifers for reproduction. The delayed differentiation strategy consists of designing products so that, for a given variety of products offered on the market, the variety of intermediate products created during the different phases is minimized (Tarondeau 1999; Fig. 4).

In figure 4 , process 1 (P1) can be assimilated to the process needed to produce the $\mathrm{F}_{1-2}$ withheld for reproduction, or by minor changes, through the process 2 (P2) to produce the "Génisse Saint Etienne" or through the process 3 (P3) to produce the "Génisse de Lyon". In particular, as the genetic qualities of the herd progress, the possibility of selling heifers for reproduction has become an important competitive advantage for these farms. 
Fig. 3. Product mix of the Limousin beef system.

\begin{tabular}{|l|} 
Beef categories \\
Females ( $\mathrm{F}$ ) 0-3 years
\end{tabular}

The sale of heifers for reproduction is a segment with more added value than the fat heifer (Table 2).

This form of product flexibility allows high variety and quick response time (Gupta and Benjaafar 2004), changing the competitive strategy of the firm from economies of scale to economies of scope. In fact, there are many advantages in the sale of females for reproduction:

- The advantages of registration and qualification in the herd book, in a competitive environment, represent barriers to the admission of potential new entrants onto the market;

- $\quad$ The added value of the "brand image" specific to livestock in an extensive system with permanent natural grasslands is transformed into a competitive advantage and takes on value for the farm;

- Direct sale to other livestock farmers means that it is the farmer who fixes the sale price. Furthermore, direct contact with the demand side also improves forecasting systems: for instance, a firm can reduce the level of uncertainty under which it works but, at the same time, it can prepare itself to respond faster to future customer orders (Corrêa and
Slack 1996) by having better demand information before committing generic semifinished products to unique products (Gupta and Benjaafar 2004).

The way to cope with variability of outputs in the Limousin extensive farming systems is by product differentiation, in this case facilitated by the plasticity of the Limousin female and the ability of the system to reschedule production without increasing operating expenses such as extra feed or specific equipment. This kind of external flexibility allowed by the enlargement of land area, illustrates how ordinary activities undertaken by farmers can be seen as strategies to take advantage of a changing environment. Mix flexibility is appropriate with regard to market requirements but it does not adequately deal with severe uncertainties within the process characteristics.

\section{Land use changes (process by routing flexibility)}

Beef suckler systems that rely exclusively on permanent pastures are very sensitive to extreme climatic events such as droughts because their viability depends mainly on their feed selfsufficiency (Baumont et al. 2008). Given the 
Fig. 4. Delayed diversification process $(\mathrm{P})$ for the different outputs $(\mathrm{O})$ produced by the Limousin extensive beef cattle farming systems (adapted from Fouquart 2002).

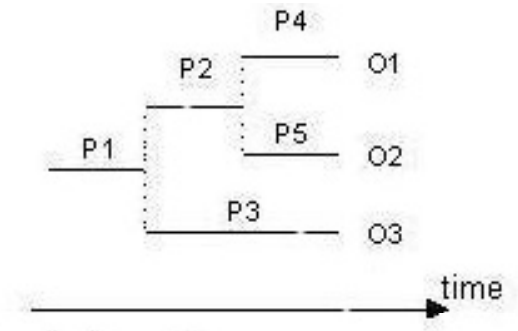

a) Early diversification process: each process corresponds to a specific output

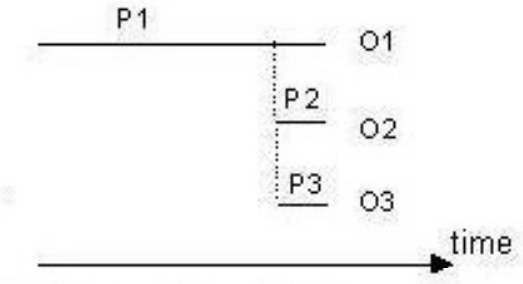

b) Delayed diversification: a unique process almost every time

P1 process to produce Output 1 (Female for reproduction)

P2 process to produce Output 2 (Genisse St. Etienne)

$P 3$ process to produce Output 3 (Genisse de Lyon) constraints of a continental climate, the production of herbage is concentrated in spring and summer. Thus, the animal production cycle and the forage system are managed so as to exploit herbage growth for grazing and also for the harvest of hay. During the winter period (five to six months), the herd is housed and fed with conserved forage. The amount and quality of the hay harvested should be sufficient to feed the cows during late pregnancy and early lactation, which usually occur in winter. The function of the forage system is to provide continuous feed in spite of fluctuations in the supply of forage associated with fluctuations in the climate, while the demand for feed remains relatively stable for a constant animal population (Duru et al. 1988). A drought in summer and spring is very harmful to these systems in which farmers depend on high yields for the first hay cut and are not used to sparing standing forage for grazing in summer.

In recent years, farmers have had to confront two serious droughts, those of 2003 and 2005, that placed great stress on their forage system. The drought in 1976 had been experienced as an exceptional event. The more recent droughts in the early 1990s and especially those of 2003 and 2005 were seen more as one of the possible manifestations of climate change, forecasting a more frequent return of these anomalies that, from the status of exceptional catastrophe, could move to the status of recurrent phenomenon (Amigues et al. 2006). As was highlighted in the interviews, the drought itself was not what the livestock farmer fears, but more its random nature: in which season will the drought occur and how serious will it be? Using the taxonomy proposed by Corrêa and Slack (1996) for disturbances from the environment, drought appears to farmers to be a change that risks becoming "frequent", "unpredictable" and "drastic" (the rate of unplanned change). This could become a weakness for systems that have to ensure a stable production flow. Therefore, another type of flexibility at overall system level is required to maintain output in spite of unplanned changes with the process itself. The uncertainty of forage production from native grasslands as a result of climate fluctuations acted as a driver for process flexibility.

The studied cases can be grouped according to the stocking rate in two categories: low stocking rate and high stocking rate, but always below 1.1 LU/ha (Table 3).

\section{Systems with lower stocking rates}

The systems with lower stocking rates, based on permanent pasture, show some leeway that allows them to 'tolerate' drought better because of the lower stocking rate used in the system. As farmers 
Table 2. Average prices of the Limousin females (F) sold for reproduction or for fattening.

\begin{tabular}{ccccc}
\hline \hline & $\begin{array}{c}\text { F 2-3 } \\
\text { (pregnant) }\end{array}$ & $\begin{array}{c}\text { F 1-2 } \\
\text { (for reproduction) }\end{array}$ & $\begin{array}{c}\text { F 1-2 } \\
\text { (fattened) }\end{array}$ & $\begin{array}{c}\text { F 0 -1 } \\
\text { (for fattening) }\end{array}$ \\
\hline $\begin{array}{c}\text { Average price } \\
\text { (Euros 2005) }\end{array}$ & 1811 & 1522 & 1470 & 767 \\
\hline
\end{tabular}

pointed out, the strategy followed in those cases was to reduce or to eliminate the production of crops as a way of increasing the area under grass, principally for forage conservation, such as hay. Generally, the area recovered for this purpose is intensively worked with short rotation productive grasses, such as annual ryegrasses. These are operational changes and represent an operational flexibility, i.e., routine capabilities that are based on present structures. This strategy relates to changes in volume activities rather than changes in the kind of activities undertaken within the farm.

From the viewpoint of the analysis of flexibility, the reduction or elimination of crop production can also be analyzed according to the interest of these farms for buying cereals or mixtures prepared by specialized suppliers:

- It is an ordinary activity that enables the cost of the external transaction, even if it is higher than the cost of the internal transaction, to be a valid option because it improves the production of quality hay under the control of the farmer;

- The margin of the Forage Area, because of aids received by the suckler farm, is higher than the margin for arable crops (Veysset et al. 2005);

- Specialization makes it possible to have partnerships with suppliers for volumes defined annually and a reduction in the risk associated with arable crop activities.

\section{Systems with higher stocking rates}

For farms with higher stocking rates, major changes are needed to deal with drought. Not only does the technology of forage production change, but the feeding system changes too. In these latter cases, the introduction, or the increase, of maize silage represents a change in actual capabilities and the structure of the system. These changes represent a strategic, more qualitative flexibility necessary when changes have far-reaching consequences and a speedy response is needed. The introduction of maize silage for feed and the forage stocks that it allows, act as a preventive method and as an alternative route, actual and potential, through the system to overcome unexpected forage shortage from natural grasslands as a result of droughts (Fig. 5).

Process flexibility has frequently been studied and appears in both dimensions such as process routing, i.e., routing is often defined in terms of the ability to use alternative routes through the system in case of a malfunction, and sequencing (Gupta and Somers 1996). Miltenburg (2003) proposes the following definition of process flexibility: the number of products that have alternative processing plans and the variety of processing operations used without incurring negative effects, e.g., changes in performance outcomes, when fluctuations arise. Process flexibility is related to the "slack" in land production capacity normally exploited compared to intensive land use conditions. Slack is a pool of system resources in excess of the minimum necessary to produce a given level of an output. Redundant resources can provide a cushion that allows organizations to adjust successfully to internal pressures as well as to initiate strategy with respect to the external environment (Zinn and Barry Flood 2009). Therefore, in these extensive farming systems, a relatively small area of maize as a percentage of total land use enables the constitution of enough forage stocks to avoid or minimize the deleterious effects of unexpected droughts. In other words, to become intensive in a reduced part of the farm makes it possible to stay extensive at system or whole farm scale. 
Table 3. Main changes in the extensive beef cattle farming systems studied to cope with droughts.

\begin{tabular}{lcc}
\hline \hline & Stocking rate (LU/ha) \\
\cline { 2 - 3 } & less than 1.00 & more than 1.00 \\
\hline $\begin{array}{l}\text { Changes to cope } \\
\text { with drought }\end{array}$ & $\begin{array}{c}\text { decreasing stocking rate by reducing or } \\
\text { eliminating areas under crops }\end{array}$ & $\begin{array}{c}\text { increasing forage production by including or } \\
\text { increasing area for maize silage }\end{array}$ \\
Farms & 4 and 5 & $2,3,6$, and 7 \\
\hline
\end{tabular}

As decision making on farms is under direct influence from humans, this process is decisively influenced by the farmer's perceptions, preferences, and risk aversion (Darnhofer et al. 2010b). If we take into account the timing of change, some differences in farmer behavior can be observed in our study (Table 4).

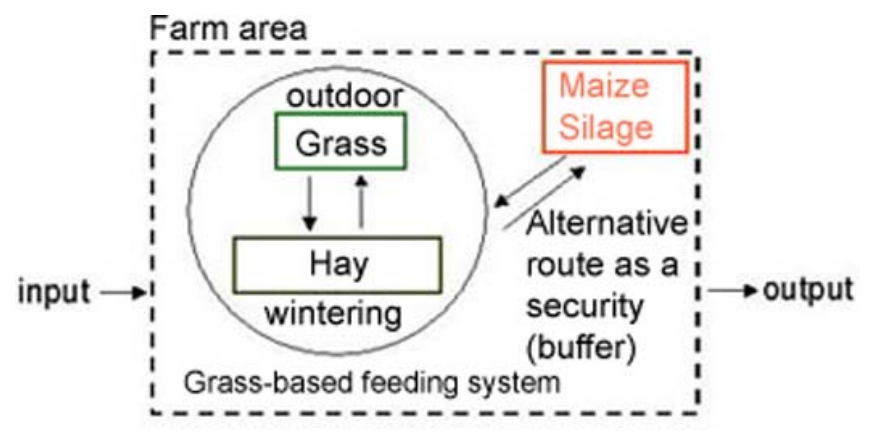

Fig. 5. Routing process, or sequencing, of the feeding system with maize silage.

Farm 5, faced with the drought, tended to act quickly in a proactive way, but with a moderate change, i.e., crop area reduction. On the other hand, farm 7 acted more slowly, but with a more profound change, i.e., introduction of maize silage. We can distinguish different levels of change in the system based on the perception of the farmer on how severe and frequent the changes in the environment might be. The use of this type of system flexibility to cope with uncertainty and variability of outputs appeared to be highly contingent on the individual manager's view and experience. Facing the same stimuli, the system response may vary according to a certain threshold level as perceived by the manager (De Leeuw and Volberda 1996): 1) if this threshold level is not reached, the management acts prudently instead of decisively and prefers to implement change slowly and steadily; or 2) if this threshold level is reached, the management seeks to limit the variability from the environment by developing preventive methods and therefore reducing uncertainty as opposed to investing in quick corrective methods.

According to Volberda (1996), the capacity to respond by deliberate postponement of decisions could result in a lack of decisiveness, progressively increasing costs, and a continuous revision of plans. On the other hand, too great a reaction capacity or too short a reaction time may lead to overreaction and wasted resources. Achieving process flexibility may result in additional costs to the farm, so the challenge should be that the sufficiency of the system flexibility developed must match the degree of the environmental turbulence.

\section{CONCLUSION}

This paper attempts to contribute to the study of farm system flexibility and to understand the drivers of flexibility and their effect on farm system design. The concept of flexibility encompasses many of the temporal considerations that influence farmer decision making: the system flexibility that exists at any time results from decisions taken at earlier points in time, mixing learning and feedback mechanisms. 
Table 4. Timing and extent of change to deal with drought for two of the farms analyzed.

\begin{tabular}{cccccc}
\hline \hline & \multicolumn{2}{c}{ Farm 5 } & & \multicolumn{2}{c}{ Farm 7 } \\
\cline { 2 - 3 } \cline { 5 - 6 } Reactive response & Drought 2003 & Drought 2005 & & Drought 2003 & Drought 2005 \\
\hline Proactive response & $\begin{array}{c}\text { Decrease of crop area } \\
\text { (8 to 5\% total area) }\end{array}$ & Nurchase of hay & & Use of stocked hay & Use of stocked hay \\
& & & No response & $\begin{array}{c}\text { Introduction of maize } \\
\text { for silage (7\% total } \\
\text { area) }\end{array}$ \\
\hline
\end{tabular}

The study shows that extensive beef cattle farming systems have developed types of flexibility to match different factors of uncertainty from the environment. From the cases studied, the actual and potential procedures used by farmers to allocate to flexibility-need allowed by individual resources are:

- a wider product line and a capacity to switch from one product to another, acting as a cushion effect if the demand for one product line shrinks unexpectedly;

- $\quad$ a land area that acts as a buffer system and allows alternative routes, actual and potential, through the system to overcome unexpected forage shortage as a result of droughts.

For the system, maintaining diversity and redundancy are an insurance against uncertainty, implying a higher level of security with respect to environmental fluctuations. However, these levels of security vary between farms according to human perception of risk threshold, and are related to aspects of management and organization of the system.

Finally, the issue of farm system flexibility is thus not so much a question of whether a farm is fit at a specific moment in time, but more whether the system preserves a relative capacity to respond or conform to changing circumstances. Some of the examples presented in our work are ordinary activities, such as diversification, that can be analyzed under classical farm management perspective. Nevertheless, the interest in introducing the concept of flexibility used for the analysis of firms facing change is to enlarge this perspective into an adaptive perspective of farm management. Flexibility can be seen as a quality of adaptive management that emphasizes the importance of understanding feedback from the environment and systematic, i.e., not-random, experimentation in shaping future actions.

Responses to this article can be read online at: http://www.ecologyandsociety.org/vol16/iss1/art7/responses/

\section{Acknowledgments:}

This work was carried out with the financial support of the ANR (Agence Nationale de la Recherche-The French National Research Agency) under the "Programme Agriculture et Développement Durable" project ANR-05-PADD-04-01 Discotech. The authors wish to thank the two anonymous reviewers and the editor for their helpful comments that contributed to making our work more comprehensive.

\section{LITERATURE CITED}

Amigues, J. P., P. Debaeke, B. Itier, G. Lemaire, B. Seguin, F. Tardieu, and A. Thomas, editors. 2006. Sécheresse et agriculture. Réduire la vulnérabilité 
de l'agriculture à un risque accru de manque d'eau. Expertise scientifique collective, synthèse du rapport, INRA, France.

Baumont, R., M. Jouven, N. Deux, and A. Farruggia. 2008. How can farms with beef cattle systems based on permanent pasture cope with extreme climatic years? Results of a study using the whole-farm simulator SEBIEN. Pages 435-444 in B. Dedieu and S. Zasser-Bedoya, editors. Proceedings of the 8th European International Farming Systems Association Symposium. 8-10 July 2008, INRA SAD, ClermontFerrand, France.

Brouard, S. 2006. Note de synthèse sur les évolutions conjoncturelles. Actualisation 2005 des résultats économiques des systèmes d'élevage Bovin en Limousin. Institut de l'Elevage, Paris, France. [online] URL: http://www.inst-elevage.asso. fr/html1/spip.php?article9971.

Cattani, K., E. Dahan, and G. Schmidt. 2002. Spackling: smoothing make-to-order production of custom products with make-to-stock production of standard items. Anderson Graduate School of Management, University of California, Los Angeles, California, USA.

Corrêa, H. L., and N. Slack. 1996. Framework to analyse flexibility and unplanned change in manufacturing systems. Computer Integrated Manufacturing 9(1):57-64.

Darnhofer, I., S. Bellon, B. Dedieu, and R. Milestad. 2010a. Adaptiveness to enhance the sustainability of farming systems. A review. Agronomy for Sustainable Development 30(3):545-555.

Darnhofer, I., J. Fairweather, and H. Moller. $2010 b$. Assessing a farm's sustainability: insights from resilience thinking. International Journal of Agricultural Sustainability 8(3):186-198.

Das, S., and P. Patel. 2002. An audit tool for determining flexibility requirements in a manufacturing facility. Integrated Manufacturing Systems 13 (4):264-274.

Dauplais, P. 1996. Elements de reflexion sur l'orientation de la race Limousine. Bovins Limousins 127:12-14.

Dedieu, B., E. Chia, B. Leclerc, C. H. Moulin, and M. Tichit, editors. 2008. L'élevage en mouvement: flexibilité et adaptation des exploitations d'herbivores. Édition Quæ, Collection Update Sciences \& Technologies, Versailles, France.

De Leeuw, A. C. J., and H. W. Volberda. 1996. On the concept of flexibility: a dual control perspective. Omega, International Journal of Management Science 24(2):121-139.

Dreyer, B., and K. Grønhaug. 2004. Uncertainty, flexibility and sustained competitive advantage. Journal of Business Research 57:484-494

Duru, M., J. Nocquet, and A. Bourgeois. 1988. Le système fourrager: un concept opératoire?. Fourrages 115:251-272.

Fouquart, I. 2002. La flexibilité dans les systèmes de production. DESS Gestion et Pilotage de la Production. IUP de Lorient, France.

García-Martínez A., A. Olaizola, and A. Bernué. 2009. Trajectories of evolution and drivers of change in European mountain cattle farming systems. Animal 3 (1):152-165.

Geay, Y., and D. Micol. 1982. Les principaux types de production de viande en race bovine limousine. Bulletin Technique CRZVTheix, INRA 48:125-130.

Gerwin, D. 1993. Manufacturing flexibility: a strategic perspective. Management Science 39 (4):395-410.

Gjerding, A. N. 1999. The evolution of the flexible firm. National Innovation Systems, Industrial Dynamics and Innovation Policy. Danish Research Unit for Industrial Dynamics, Rebild, Denmark. [online] URL: http://www.druid.dk/uploads/tx pic turedb/ds1999-57.pdf.

Gunderson, L. 2000. Ecological resilience - in theory and application. Annual Review of Ecological Systems 31:425-439.

Gupta, D., and S. Benjaafar. 2004. Make-to-order, make-to-stock, or delay product differentiation? A common framework for modelling and analysis. IIE Transactions 36:529-546

Gupta, Y.P., and J. A. Buzacott. 1989. A framework for understanding flexibility of manufacturing systems. Journal of Manufacturing Systems 8 (2):89-97. 
Gupta, Y. P., and T. M. Somers. 1996. Business strategy, manufacturing flexibility, and organizational performance relationships: a path analysis approach. Production and Operations Management 5(3):204-233.

Holling, C. S. 1973. Resilience and stability of ecological systems. Annual Review of Ecology and Systematics 4:1-23.

Ingrand, S., H. Bardey, and J. Brossier. 2007. Flexibility of suckler cattle farms in the face of uncertainty within the beef industry: a proposed definition and an illustration. The Journal of Agricultural Education and Extension 13(1):39-48.

Josien, E., B. Dedieu, C. Chassaing, and P. Babaudou. 1994. Réseaux extensif bovin Limousin: caractéristiques générales des exploitations et éléments de réflexion. Fourrages 137:3-23.

Lev, L., and D. Campbell. 1987. The temporal dimension in farming systems research: the importance of maintaining flexibility under conditions of uncertainties. Journal of Rural Studies 3(2):123-132.

Milestad, R. 2003. Building farm resilience. Dissertation. Department of Rural Development Studies, Swedish University of Agricultural Sciences, Uppsala, Sweden.

Milestad, R., and I. Darnhofer. 2003. Building farm resilience: the prospects and challenges of organic farming. Journal of Sustainable Agriculture 22 (3):81-97

Miltenburg, P. 2003. Effects of modular sourcing on manufacturing flexibility in the automotive industry. Dissertation. Erasmus Research Institute of Management (ERIM) PhD Series Research in Management 30. [online] URL: http://repub.eur.nl/ resource/pub 1039/index.html.

Pujawan, N. 2004. Assessing supply chain flexibility: a conceptual framework and a case study. International Journal of Integrated Supply Management 1(1):79-97.

Scala, J., L. Purdy, and F. Safayeni. 2006. Application of cybernetics to manufacturing flexibility: a systems perspective. Manufacturing Technology Management 17(1):22-41.
Slack, N. D. C. 1987. Manufacturing systems flexibility: ten empirical observations. Working Paper No. MRP87/9. Oxford Centre for Management Studies, Templeton College, Oxford University Press, Oxford, UK.

Suárez, F., M. Cusumano, and C. Fine. 1996. An empirical study of manufacturing flexibility in printed-circuit board assembly. Operational Research 44(1):223-240.

Tarondeau, J. C. 1999. Flexibilité dans les entreprises. Collection Que Sais-Je? N 3477. Presses Universitaires de France, Paris, France. ISBN 2130499724.

Upton, D. M. 1994. Management of manufacturing flexibility. California Management Review 36 (2):72-89.

Veysset, P., M. Lherm, and D. Bebin. 2005. Evolutions, dispersions et déterminants du revenu en élevage bovin allaitant charolais. Etude sur 15 ans (1989-2003) à partir d'un échantillon constant de 69 exploitations. INRA Productions Animales 18 (4):265-275.

Volberda, H. 1996. Towards the flexible form: how to remain vital in hypercompetitive environments. Organisation Science 7(4):359-374.

Wadhwa, S., and K. S. Rao. 2002. Framework for a flexibility maturity model. Global Journal of Flexible Systems Management 3(2/3):45-53.

Zinn, J., and A. Barry Flood. 2009. Commentary: slack resources in health care organizations- fat to be trimmed or muscle to be exercised? Health Services Research 44:(3). [online] URL: http://find articles.com/p/articles/mi m4149/is 3 44/ai n32064807/ 